\title{
Recent achievement on the editorial time
}

\author{
Takashi Saitoh
}

Received: 3 July 2011/Accepted: 14 November 2011/Published online: 29 November 2011

(C) The Society of Population Ecology and Springer 2011

We are pleased to report on a recent achievement on the editorial time between the receipt of a manuscript and return of the first report to authors. The average time $( \pm S D)$ was shortened to 31.6 days $( \pm 27.8)$ in 2010 from 38.3 days $( \pm 27.7)$ in 2009 . The first round of review for 120 manuscripts $(83.9 \%)$ was completed within 60 days, while the number of manuscripts for which the first round of review was finished within 90 days was 139 (97.2\%). Fifty-six manuscripts $(39.2 \%)$ were rejected by editors before being sent to reviewers.

The average amount of time taken to complete the first round of reviews has steadily declined over the last 4 years (Fig. 1; see also Fig. 2 in Saitoh 2010). The frequency distribution of editorial duration time in 2010 was close to our goal; the first peak corresponds to rejection by editors before being sent to reviewers and the second was the mode for the time between the receipt of a manuscript and return of the first reviewers' report. Although we know that authors prefer quick decisions, it is important to recognize that sufficient time is required to obtain meaningful reviews. We believe that 60 days for the first round of reviews may be acceptable to both authors and reviewers.

\section{Other editorial statistics}

During the year 2010, a total of 143 manuscripts were submitted from authors located in 38 different countries. Thirtyone $(21.7 \%)$ manuscripts each originated from both North America and Europe followed by Asia other than Japan (24,

T. Saitoh $(\bowtie)$

Field Science Center, Hokkaido University,

North 11, West 10, Sapporo 060-0811, Japan

e-mail: tsaitoh@fsc.hokudai.ac.jp
$16.8 \%)$ and Japan $(23,16.1 \%)$. The rate of acceptance was $35.0 \%$ for non-invited papers excluding manuscripts for special features. Rates of acceptance of manuscripts from North America, Europe and Japan were higher than average.

\section{Interactive publications}

We are encouraging readers to provide critical comments on articles published in Population Ecology. Four critical comments (Cayuela et al. 2011; Devink et al. 2011; Hargraove et al. 2011; McKelvey et al. 2011) on three recent articles (Brodie and Post 2010; Baltolino et al. 2011a; Barclay and Vreysen 2011a) were published in the previous volume. Because responses from authors are often essential for reaching a deep understanding of the points raised by the critical comments, the critical comments were published along with responses in the same issue (Brodie and Post 2011; Baltolino et al. 2011b; Barclay and Vreysen 2011b). We anticipate that such interactive publications may foster insightful debates in science.

\section{Photos on the cover page}

One photo was selected from an article published in 2010 and three others were selected from the previous volume published in 2011.

Endemic to southeastern Nigeria, Sclater's monkey (Cercopithecus sclateri; upper left) is listed as vulnerable by the IUCN Red List. The species does not occur in any official protected areas, but it is protected locally in three communities through cultural taboos (Baker et al. 2011). Here it is seen in one of these sites: Lagwa, Aboh Mbaise Local Government Area, Imo State. 


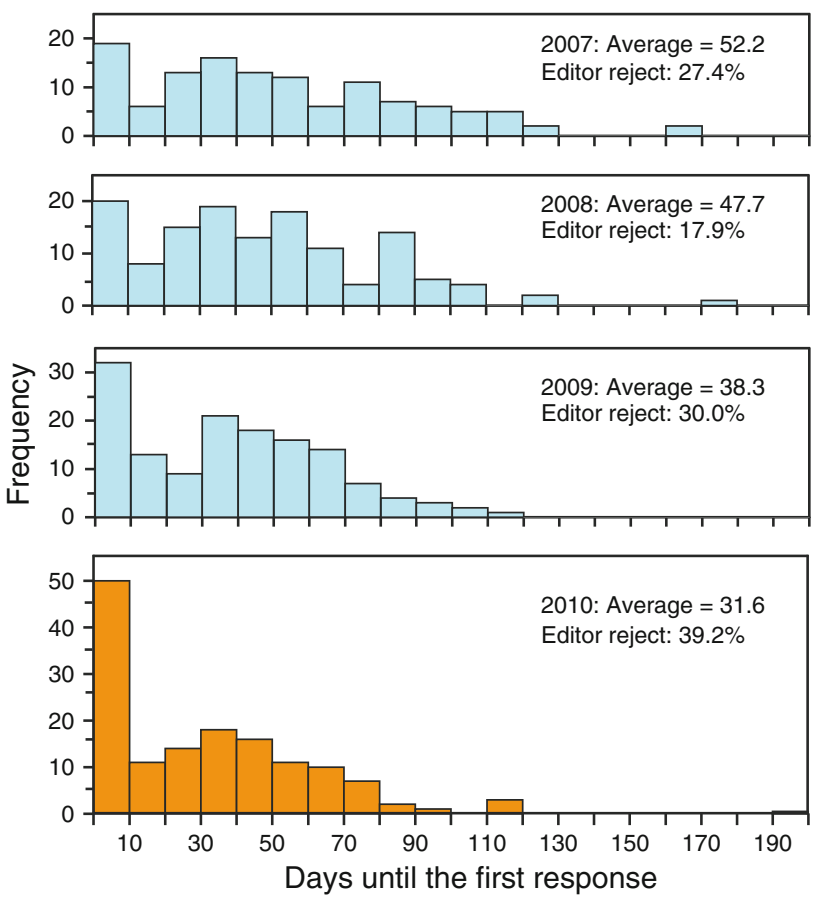

Fig. 1 Frequency distribution of the editorial time between the receipt of a manuscript and return of the first report to authors for 4 years (2007-2010). "Editor reject" indicates rejection by editors before being sent to reviewers

The colony size of the Brazilian swarm-founding wasp Polybia paulista often exceeds several thousand wasps (upper right). Colony size of this species is highly variable and experiences substantial reductions in worker numbers from summer to winter. Differences in survivorship patterns among worker cohorts would be related to worker foraging activity and/or level of parasitism (Kudô et al. 2011).

He and Lamont (2010) revealed that allelic richness of Daviesia triflora (lower left), an ant-dispersed pea native to Southwest Australia, covaries positively with the species richness of co-occurring nitrogen-fixing legume species. The photo shows a mass flowering individual of $D$. triflora in a habitat with up to six other legume species co-occurring.

Male White-tailed Ptarmigan in the Yukon Territory, Canada (lower right). Females from northern populations in the Yukon lay larger clutches of smaller eggs and have higher annual fecundity than females in Colorado, but they also have lower annual survival rates. These differences suggest a life history shift between the two ends of the species geographic range (Wilson and Martin 2011).

\section{References}

Baker LR, Arnold TW, Olubode OS, Garshelis DL (2011) Evolutionary variations on a theme: host plant specialization in five geographical populations of the leaf beetle Chrysomela lapponica. Popul Ecol 53:549-561

Baltolino V, Maiorano L, Colloca F (2011a) A frequency distribution approach to hotspot identification. Popul Ecol 53:351-359

Baltolino V, Maiorano L, Colloca F (2011b) Frequency distribution curves and the identification of hotspot: response to comments. Popul Ecol 53:603-604

Barclay HJ, Vreysen MJB (2011a) A dynamic population model for tsetse (Diptera: Glossiinidae) area-wide integrated pest management. Popul Ecol 53:89-110

Barclay HJ, Vreysen MJB (2011b) Conclusions from a dynamic population model for tsetse: response to comments. Popul Ecol 53:417-420

Brodie JF, Post E (2010) Nonlinear responses of wolverine populations to declining winter snowpack. Popul Ecol 52:47-58

Brodie JF, Post E (2011) Wolverines and declining snowpackresponse to comments. Popul Ecol 53:267-269

Cayuela L, Gálvez-Bravo L, Carrascal LM, de Albuqerque FS (2011) Comments on Bartolino et al (2011) Limits of cumulative relative frequency distribution curves for hotspot identification. Popul Ecol 53:597-601

DeVink J-M, Berezanski D, Imrie D (2011) Comments on Brodie and Post: harvest effort: the missing covariate in analyses of furbearer harvest data. Popul Ecol 53:260-261

Hargraove JW, Torr SJ, Vale GA (2011) Comment on Barclay and Vreysen: published dynamic population model for tsetse cannot fit field data. Popul Ecol 53:413-415

He T, Lamont BB (2010) Species versus genotypic diversity of a nitrogen fixing plant functional group in a metacommunity. Popul Ecol 52:337-345

Kudô K, Koji S, Mateus S, Zucchi R, Tsuchida K (2011) Worker demography in a large-colony, swarm-founding wasp. Popul Ecol 53:297-306

McKelvey KS, Lofroth EC, Copeland JP, Aubry KB, Magoun AJ (2011) Comments on Brodie and Post: climate-driven declines in wolverine populations: causal connection or spurious correlation? Popul Ecol 53:262-266

Saitoh T (2010) Editorial: special features and issues. Popul Ecol 52:1-3

Wilson S, Martin K (2011) Life-history and demographic variation in an alpine specialist at the latitudinal extremes of the range. Popul Ecol 53:459-471 